\title{
Repression of Fgf Signaling by Sprouty1-2 Regulates Cortical Patterning in Two Distinct Regions and Times
}

\author{
Andrea Faedo, Ugo Borello, and John L. R. Rubenstein \\ Nina Ireland Laboratory of Developmental Neurobiology, Department of Psychiatry, University of California, San Francisco, San Francisco, \\ California 94158-2611
}

A fundamental question in developmental biology is how signaling pathways establish a transcription factor code that controls cell proliferation, regional fate and cell fate. Morphogenesis of the rostral telencephalon is controlled in part by Fgf signaling from the rostral patterning center. How Fgf signaling is regulated in the telencephalon is critical for understanding cerebral cortex formation. Here we show that mouse Sprouty1 and Sprouty2 (Spry1-2), which encode negative feedback regulators of Fgf signaling, are affecting cortical proliferation, differentiation, and the expression of genes regulating progenitor identity in the ventricular zone. In addition, Spry 2 has a later function in regulating the MAPK pathway, proliferation, and gene expression in the cortex at mid-neurogenesis. Finally, we provide evidence that Coup-TFI, a transcription factor that promotes caudal fate, does so through repressing Fgf signaling, in part by promoting Spry expression.

\section{Introduction}

Fibroblast growth factor (Fgf) signaling during embryogenesis has a central role in regulating regional specification and morphogenesis of the forebrain (Shimamura and Rubenstein, 1997; Ye et al., 1998; Crossley et al., 2001; Fukuchi-Shimogori and Grove, 2001; Korada et al., 2002; Garel et al., 2003; Mason, 2007). At least five Fgf ligands ( $F g f 3, F g f 8, F g f 15, F g f 17$, and $F g f 18$ ) are expressed in a nested pattern in the rostral patterning center (RPC) (Cholfin and Rubenstein, 2007), a neuroepithelial region of the telencephalon that is derived from the anterior-most neural plate. In addition, some Fgf ligands, such as Fgf10, are more broadly expressed, and regulate neuroepithelial differentiation (Sahara and O'Leary, 2009).

Alterations in Fgf signaling (in Fgf receptor mutants) (Hébert et al., 2003; Sansom et al., 2005; Gutin et al., 2006; Smith et al., 2006; Thomson et al., 2009) or Fgf ligand dosage alter telencephalic regional patterning and growth. Whereas reduced $F g f 8$ and Fgf17 caudalize the cortex (Garel et al., 2003; Storm et al., 2006; Cholfin and Rubenstein, 2007, 2008), reduced Fgf15 has the opposite phenotype (Borello et al., 2008). Some of these phenotypes are controlled by alterations in the expression of Coup-TFI, a transcription factor with caudoventralizing, antiproliferative, and neurogenic properties (Armentano et al., 2007; Faedo et al., 2008).

Received Jan. 19, 2010; accepted Jan. 28, 2010.

This work was supported by the research grants to J.L.R.R. from Nina Ireland, Weston Havens Foundation, and National Institute of Neurological Disorders and Stroke Grant NS34661 and by grants from National Alliance for Research on Schizophrenia and Depression (A.F. and U.B.) and Autism Speaks (J.L.R.R. and U.B.). We thank Renee Hoch and members of the Rubenstein laboratory for helpful discussions and Gail Martin for advice and providing the Sprouty mutant mice.

Correspondence should be addressed to either John L. R. Rubenstein or Andrea Faedo at the above address, E-mail: john.rubenstein@ucsf.edu or andrea.faedo@ucsf.edu.

U. Borello's present address: Department of Development and Neurobiology Institute Jacques-Monod CNRS UMR 7592, Université Paris Diderot, Bâtiment Buffon, 15 rue Hélène Brion, 75205 Paris Cedex 13, France.

DOI:10.1523/JNEUROSCI.0307-10.2010

Copyright $\odot 2010$ the authors $\quad 0270-6474 / 10 / 304015-09 \$ 15.00 / 0$
Fgfs signal through four Fgf receptors (FgfRs), which activate several transduction pathways, including the Ras-Erk, the PI3 kinase-Akt, and the PLC-calcium-PKC pathways (Mason, 2007). We presented evidence that Coup-TFI is a negative regulator of Ras-Erk and PI3 kinase-Akt signaling (Faedo et al., 2008), suggesting that Coup-TFI regulates cortical patterning, proliferation, and neurogenesis, at least in part through repression of Fgf signaling.

The four Spry genes are induced by Fgf signaling and serve as negative feedback regulators. Spry proteins function intracellularly to inhibit the Ras-MAPK pathway, although their precise biochemical mechanism(s) remains controversial (Kim and BarSagi, 2004; Mason, 2007). Loss-of-function analyses in mice have shown that Spry genes are required for development of the midbrain/hindbrain, kidney (Basson et al., 2005), auditory epithelium (Shim et al., 2005), and tooth (Klein et al., 2006). Their roles in telencephalic development are unknown.

$F g f 8$ is required for Spryl expression in the RPC (Storm et al., 2006), while $F g f 17^{-1-}$ mutants do not show an obvious change in Spry1 or Spry2 expression (Cholfin and Rubenstein, 2008). Spry2 expression in ventral cortical progenitors is positively regulated by $F g f 15$, which is expressed at low levels at the pallial-subpallial boundary (Borello et al., 2008). Fgf15 also promotes the expression of Coup-TFI (Borello et al., 2008), unlike Fgf8 and Fgf17, which repress Coup-TFI (Garel et al., 2003; Cholfin and Rubenstein, 2008). Moreover, Coup-TFI represses Erk phosphorylation when overexpressed (Faedo et al., 2008). Thus, here we investigated how Coup-TFI regulates Fgf signaling.

We demonstrate different functions of Spry during cortical development. First, we show that Spry1 and Spry2 expression in the RPC function together as negative regulators of Fgf signaling from the RPC to control early patterning, proliferation, differentiation, and progenitor identity of the rostral dorsal/medial pallium. Second, we show that Spry2 has a later function in 

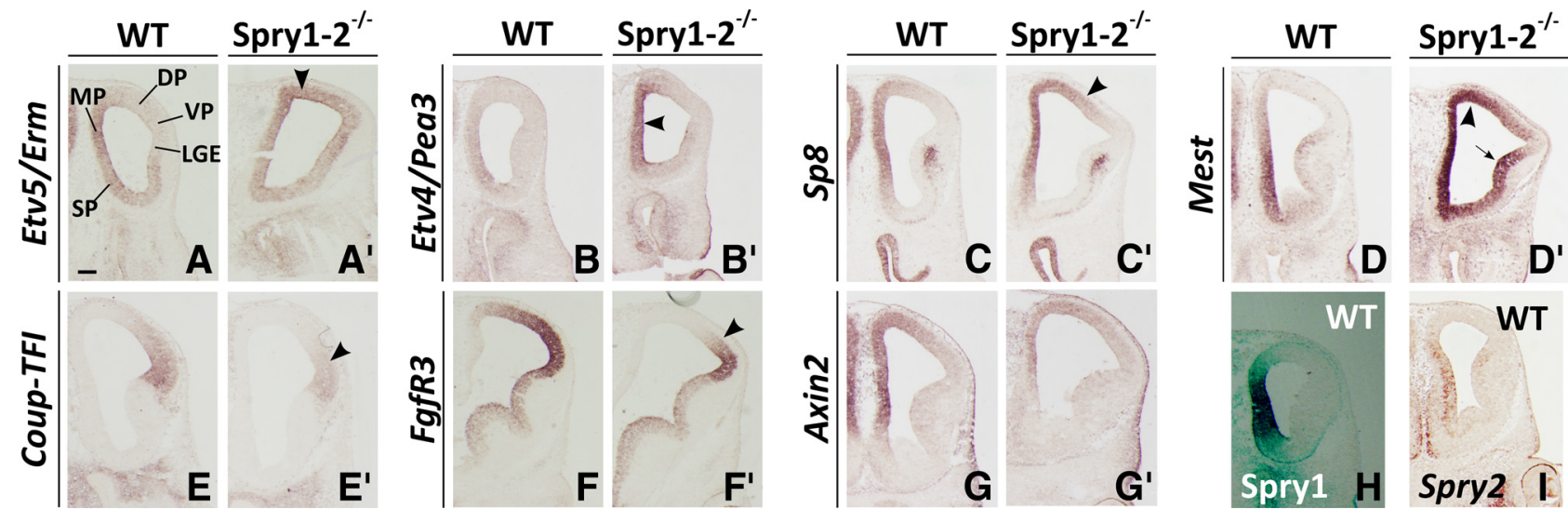

Figure 1. Spry1-2 loss of function upregulates Fgf-regulated genes in the E12.5 RPC and dorsal telencephalon. $\boldsymbol{A}-\boldsymbol{D}^{\prime}$, RNA in situ hybridization for Etv5 $\left(\boldsymbol{A}, \boldsymbol{A}^{\prime}\right)$, Etv4 $\left(\boldsymbol{B}, \boldsymbol{B}^{\prime}\right), \operatorname{Sp8}\left(\boldsymbol{C}, \boldsymbol{C}^{\prime}\right)$, and Mest $\left(\boldsymbol{D}, \boldsymbol{D}^{\prime}\right)$ showing the upregulation of Fgf-regulated genes in the medial/dorsal pallium (arrowheads in $\left.\boldsymbol{A}^{\prime}, \boldsymbol{B}^{\prime}, \boldsymbol{C}^{\prime}, \boldsymbol{D}^{\prime}\right)$. $\boldsymbol{E}, \boldsymbol{E}^{\prime}$, Coup-TFl, a gene with a complementary expression pattern to Spry1-2, and repressed by Fgf signaling, is downregulated. $\boldsymbol{F}^{\prime} \boldsymbol{F}^{\prime}, F$ frr3 expression, similar to Coup-TFI, and repressed by Fgf signaling, is shifted ventrally $\left(\boldsymbol{F}^{\prime}\right.$ arrowhead). $\mathbf{G}, \boldsymbol{G}^{\prime}$, Axin2 $\mathrm{RNA}$ expression can be used as WNT signaling readout: in Spry1-2 $2^{-1-}$ its reduced expression suggests that Fgf signaling represses WNT signaling. $\boldsymbol{H}, \boldsymbol{I}$, Spry 1 ( $\beta$-galactosidase staining) and Spry2 expression in WT sections. DP, dorsal pallium; VP, ventral pallium; MP, medial pallium; SP, septum; LGE, lateral ganglionic eminence. Scale bar, $200 \mu \mathrm{m}$.

regulating patterning and proliferation of the dorsal/ventral pallium through its expression in pallial progenitors. Finally, we show that Coup-TFI overexpression induces Spry2, which mediates some of Coup-TFI's repressive properties on Fgf signaling (inhibition of Erk phosphorylation, proliferation, and Etv gene transcription).

\section{Materials and Methods}

Mice. D6/Coup-TFI mice were described by Faedo et al. (2008). Briefly, to generate D6/COUP-TFI transgenic mice, a $5.7 \mathrm{~Kb}$ promoter region was cloned upstream of COUP-TFI open reading frame. The D6/COUP-TFI expression cassette was purified and injected into the pronucleus of fertilized (C57BL/6 $\times$ BALB/c) F1 mouse oocytes. Mice were genotyped by PCR using genomic DNA from the tail of postnatal and late embryonic stages or yolk sac from earlier embryos. The mouse mutant strain with null allele of Coup-TFI (Qiu et al., 1997) was used. The Spryl ${ }^{\text {lacz }}$ strain was used (Thum et al., 2008).

The production of Spry1 and Spry2 flox alleles have been described by Basson et al. (2005) and Shim et al. (2005). Mice homozygous for Spry1-2 flox were mated to $\beta$-actin-Cre transgenic mice to generate animals carrying the Spry1-2-null allele. To generate the D6/Coup-TFI;Spry1-2 ${ }^{-/-}$line, Spry1-2 flox/flox line was mated to $\beta$-actin-Cre transgenic mice to generate Spry1-2 heterozygous mice. Spry1-2 heterozygous mice were mated to D6/Coup-TFI mice to generate Spry1-2 ${ }^{+/-}$;D6/Coup-TFI mice. Spry1$2^{+/-}$mice were mated to Spry1-2 ${ }^{+/-}$;D6/Coup-TFI mice to produce Spry1-2 $2^{-\prime-}$;D6/Coup-TFI embryos. Mice heterozygous or homozygous for Spry 1-2 were identified by PCR assays described by Basson et al., 2005, and Shim et al., 2005. For in situ hybridization or immunofluorescence, either Spry 1-2 $2^{+/-}$or Spry1-2 $2^{+/+}$were used as controls, since heterozygous mice did not show any phenotype.

For staging of embryos, midday of the day of vaginal plug formation was considered as embryonic day 0.5 (E0.5).

In situ RNA hybridization. In situ RNA hybridization was performed on frozen sections (20 $\mu \mathrm{m}$ thick) mounted on Fisher Superfrost/Plus slides. In situ RNA hybridization using digoxigenin (DIG)-labeled RNA probes was performed according to methods described at the Rubenstein laboratory website (http://physio.ucsf.edu/rubenstein/protocols/index. asp). Sections from the different genotypes shown in the figures have been processed simultaneously. In the D6/COUP-TFI, we used basal ganglia expression as an internal control to compare results between the different experiments and between experimental and WT samples.

The probes used and their sources were as follows: COUP-TFI (M. Tsai, Baylor College of Medicine, Houston, TX), Fgfr1 (P. Lonai, Weizmann Institute of Medicine, Rehovot, Israel), Etv1/Er81 (T. Jessell, Columbia University, New York, NY), Sprouty1 (G. Martin, University of
California, San Francisco, CA), Sprouty2 (G. Martin), Etv5/Erm (A. Chotteau-Lelievre, Institut de Biologie de Lille, Lille, France), Etv4/Pea3 (A. Chotteau-Lelievre), Blbp (Fabp7) (N. Osumi, Tokyo University School of Medicine, Sendai, Japan), Sp8 (K. Campbell, University of Cincinnati College of Medicine, Cincinnati, OH), Axin2 (B. Cheyette, University of California, San Franscisco, CA). Mest probe was produced in John Rubenstein's lab.

Immunohistochemistry. Immunohistochemistry was performed on frozen sections (10 or $20 \mu \mathrm{m}$ thick) mounted on Fisher Superfrost/Plus slides. The slices were washed in PBS solution (PBS 0.1 M, pH 7.4), incubated in blocking solution $(0.2 \%$ Triton X-100, $10 \%$ normal goat serum, $2 \%$ nonfat milk, $0.2 \%$ gelatin in PBS) for $1 \mathrm{~h}$, and incubated $1 \mathrm{~d}$ at $4^{\circ} \mathrm{C}$ in the primary antibody diluted in $0.2 \%$ Triton $\mathrm{X}-100,3 \%$ normal goat serum, $0.2 \%$ gelatin in PBS. For p44/42 Map kinase staining TBS was used instead of PBS. For Coup-TFI antibody, antigen unmasking procedure was performed by briefly boiling the section in sodium citrate 10 $\mathrm{mm}, \mathrm{pH}$ 6. The antibodies used were as follows: monoclonal anti- $\beta$ IIItubulin antibody (clone TUJ1; Covance), 1:1000; monoclonal anti-BrdU antibody (clone B44; Becton Dickinson), 1:500; anti-phospho-p44/42 Map kinase (Thr202/Tyr204) antibody (Cell Signaling Technology) 1:100; anti-phospho-histone H3 (Ser10) (Millipore) 1:200; mouse antihuman Coup-TFI (clone H8132, Invitrogen) 1:1000; rabbit anti-Blbp (Millipore Bioscience Research Reagents) 1:1000.

For fluorescent immunohistochemistry, goat anti-rabbit Alexa-488, goat anti-mouse Alexa-594, or goat anti-rat Alexa-594 antibodies (Invitrogen), diluted at 1:300, were used. Images were acquired using a Nikon Eclipse 80i fluorescent microscope using Nikon Elements Software.

BrdU pulse analysis. Single injections of BrdU (40 mg/kg i.p.) were done following standard procedures. Animals were killed $1 \mathrm{~h}$ after BrdU injection. To quantify the number of cells, sections through the rostral cortex were divided in three vertical bins $\left(200 \mu \mathrm{m}^{2}\right)$ for counting.

\section{Results}

\section{Spry1-2 regulate patterning in the RPC and the pallium}

We began our investigation into the function of Spry1-2 regulation of telencephalic development by analyzing their expression patterns in the embryonic stage (E) 12.5 telencephalon. As previously shown, Spry1 and Spry2 RNAs are expressed in the RPC along with Fgf ligands (Fig. $1 \mathrm{H}, \mathrm{H}^{\prime}$; Fig. S1 $A-F$, available at www. jneurosci.org as supplemental material) (Cholfin and Rubenstein, 2008). Spry 1 and Spry2 have overlapping but distinct expression domains: Spry 2 is expressed in the core of the RPC with Fgf 8 (Fig. $S 1 C, D$, available at www.jneurosci.org as supplemental material), whereas Spry1 expression extends rostrally and dorsally, similar 


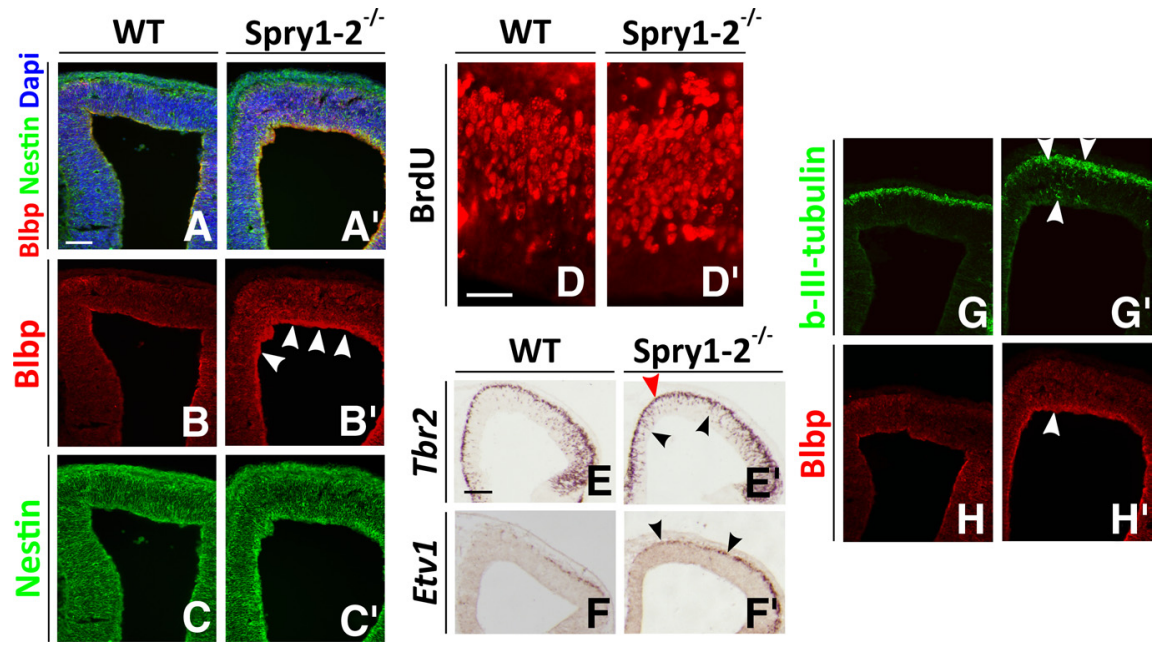

Figure 2. Spry $1-2^{-/-}$shows increased proliferation, precocious progenitor cell maturation, and neurogenesis at E12.5. $\boldsymbol{A}-\boldsymbol{C}^{\prime}$, Immunofluorescence analysis for Blbp $\left(\boldsymbol{A}-\boldsymbol{B}^{\prime}\right.$, red), and Nestin $\left(\boldsymbol{A}, \boldsymbol{A}^{\prime}\right.$ and $\boldsymbol{C}, \boldsymbol{C}^{\prime}$, green) in the WT and Spry $1-2^{-/-}$brains. Blbp, a marker for radial glia, is strongly upregulated in the dorsal/medial pallium (arrowheads in $B^{\prime}$ ). $D, D^{\prime}$, Short-pulse BrdU labeling of WT $(\boldsymbol{D})$ and Spry 1-2 $2^{-1-}\left(\boldsymbol{D}^{\prime}\right)$. BrdU was injected to pregnant females and E12.5 embryos were collected after $30^{\prime}$, and coronal sections were stained with anti-BrdU antibody. More BrdU ${ }^{+}$cells are present in the dorsal pallium in Spry $1-2^{-/-}$cortex $\left(\boldsymbol{D}^{\prime}\right)$ than in WT (D). $\boldsymbol{E}, \boldsymbol{E}^{\prime}$, RNA in situ hybridization for Tbr2 in WT and Spry1-2-/- brains, showing the increase of Tbr2 staining in preplate (red arrowhead) and in VZ/SVZ region (black arrowhead). $\boldsymbol{F}, \boldsymbol{F}^{\prime}$, RNA in situ hybridization for Etv1 in WT and Spry1-2 $2^{-1-}$ brains, showing the increase of Etv1 staining in the preplate (arrowheads). $\mathbf{G}-\boldsymbol{H}^{\prime}, \boldsymbol{\beta}$-Tubulin (green) and Blbp (red) immunodetection in WT and Spry 1-2 $2^{-1-}$ brains. Arrowheads in $\mathbf{G}^{\prime}$ point to increased preplate thickness in Spry $1-2^{-/-}$-null mice, in a region of high Blbp expression $\left(\boldsymbol{H}^{\prime}\right)$. Scale bars: $\boldsymbol{A}-\boldsymbol{C}^{\prime}, \boldsymbol{E}-\boldsymbol{F}^{\prime}, \boldsymbol{G}-\boldsymbol{H}^{\prime}, 200 \mu \mathrm{m} ; \boldsymbol{D}, \boldsymbol{D}^{\prime}, 250 \mu \mathrm{m}$.

to $F g f 17$ (Fig. S1 A, B,F, available at www.jneurosci.org as supplemental material). Moreover, we detected Spry1 expression in the dorsal pallium using the Spryl ${ }^{\text {lacz }}$ line (Thum et al., 2008) (arrowheads in Fig. S1 $A$, available at www.jneurosci.org as supplemental material).

To elucidate Spry1-2 function in telencephalic development we used Spry1, Spry2, and Spry1-2-null mutants. We studied the expression of genes that are reporters of Fgf signaling and are important for telencephalic development. Here we focused on the Spry 1-2 mutant because the phenotype was strong, although the single mutants (Spry1>Spry2) showed similar but less pronounced defects (Fig. S2, available at www.jneurosci.org as supplemental material).

We began by examining $F g f 8, F g f 15$, and Fgf10 expression in the Spry 1-2 mutants at E12.5, and did not find obvious changes (Fig. S3, available at www.jneurosci.org as supplemental material). Next, we studied the expression of two Etv transcription factors which are positively regulated by Fgf signaling: Etv5 (Erm) and Etv4 (Pea3) (Münchberg et al., 1999; Raible and Brand, 2001; Roehl and Nüsslein-Volhard, 2001; Fukuchi-Shimogori and Grove, 2003; Cholfin and Rubenstein, 2008). Etv5 and Etv4 are expressed in the RPC and adjacent cortex similar to Fgf ligands and Spry1-2 (Fig. 1A,B). In the Spry1-2-null mutant, Etv5 and Etv4 were upregulated in medial pallium and ectopically expanded in dorsal pallium (Fig. $1 A^{\prime}, B^{\prime}$, arrowheads), suggesting that Spry1-2 negatively regulate transcriptional responses to Fgf signaling in the RPC. The transcription factor $S p 8$ is expressed in the RPC and the mediodorsal pallium (Fig. 1C). Consistent with its positive regulation by Fgf8 (Storm et al., 2006; Sahara et al., 2007; Cholfin and Rubenstein, 2008), its expression is expanded in the Spry1-2 mutant (Fig. 1C'). Mest/Peg1 expression is increased by Fgf8 signaling (Sansom et al., 2005); in agreement with this, we found upregulation of Mest/Peg1 in the Spry1-2 mutants (Fig. 1D, $D^{\prime}$ ).

Next we examined the effect of loss of Spry1-2 function on the expression of genes that are repressed by Fgf signaling. Both
Coup-TFI (Fig. 1E, $E^{\prime}$ ) and FgfR3 (Fig. $\left.1 F, F^{\prime}\right)$ were expressed less in the absence of Spry1-2. Therefore, the increase of Evt4, Etv5, and $S p 8$, along with the repression of Coup-TFI and FgfR3, strongly support the model that Spry1-2 in the RPC negatively regulates Fgf signaling.

Finally, we investigated whether loss of Spry1-2 function affects other signaling pathways in addition to Fgf signaling. Fgf and Wnt signaling show a reciprocal regulation during forebrain development (Shimogori et al., 2004). Axin2 RNA expression can be used as WNT signaling readout (Jho et al., 2002). Axin2 expression decreased in Spry1-2 $2^{-/-}$mutants (Fig. $1 G, G^{\prime}$ ), providing evidence that Spry1-2 mediate cross-regulation between Fgf and Wnt signaling.

In sum, at E12.5 Spry1-2 have critical roles in regulating patterning in the rostral telencephalon by negatively regulating the expression of Fgf-responsive genes.

\section{Spry1-2 regulate proliferation, differentiation, and progenitor identity in the telencephalon} Given the roles of Spry1-2 in patterning the rostral telencephalon, and the observed changes in gene expression in the VZ, we analyzed their functions in regulating proliferation and differentiation at E12.5. First, we asked whether Spry1-2 regulate maturation of the VZ. Blbp expression begins as immature neuroepithelial cells differentiate into neurogenic radial glia (Feng et al., 1994), concomitant with the initiation of neurogenesis (Anthony et al., 2004). In Spry1-2 mutants, Blbp was strongly upregulated in the dorsal/medial pallium (Fig. $2 \mathrm{~A}-$ $B^{\prime}$, red, arrowheads), suggesting that the increased Fgf signaling promoted the transformation of neuroepithelial cells into radial glia cells (Sahara and O'Leary, 2009). On the other hand, expression of nestin (an intermediate filament present in all CNS precursors cells) did not show a marked change (Fig. $1 C, C^{\prime}$, green), showing that Spry1-2 negatively regulate the onset of Blbp expression in radial glia cells, suggesting that they repress their maturation.

We next evaluated whether loss of Spry1-2 function affected proliferation. We used a $30 \mathrm{~min}$ pulse of BrdU to label $S$ phase progenitors in the VZ and SVZ at E12.5 (Fig. 2D, $D^{\prime}$ ). Counts of BrdU labeled cells showed a statistically significant $\sim 20 \%$ increase in the number of S-phase progenitors in the rostrodorsal pallium of Spry1-2 $2^{-1-}$ mice $(n=3,76 \pm 10 \mathrm{SD}$ for WT, $93 \pm 8$ SD for Spry1-2 $\left.2^{-1-}, p<0.02\right)$.

To test whether Spry1-2 affected differentiation, we examined the expression of three early neuronal markers: Tbr2, Etv1, and $\beta$ III-tubulin. Tbr2 is a T-box transcription factor expressed in the dorsal pallium beginning with the onset of neurogenesis and the appearance of intermediate (basal) progenitor cells (IPCs) (Bulfone et al., 1999; Englund et al., 2005). Conditional ablation of Tbr2 in the developing forebrain results in the loss of IPCs and their differentiated progeny (Arnold et al., 2008; Sessa et al., 2008). We found that Tbr2's expression in Spry1-2 $2^{-/-}$brains was increased in the VZ/SVZ (Fig. $2 E, E^{\prime}$, black arrowheads), and the preplate (red arrowhead), suggesting that Spry1-2 negatively regulate differentiation of early neurons and basal progenitors. Etv1 (Er81) is a transcription factor of the ETS family positively regu- 
lated by Fgf; it has a different expression pattern from Etv4 and Etv5, as it is expressed in the preplate of the ventrolateral pallium (Fig. 2 F). In Spry1-2 $2^{-/-}$mutant brains, Etv1 was upregulated in the dorsal pallium (Fig. $2 F, F^{\prime}$, arrowheads), providing evidence that Spry1-2 repress early neurogenesis. To further explore this hypothesis, we examined $\beta$ III-tubulin expression. Indeed, there was a statistically significant increase $(p<0.02)$ in the thickness of the $\beta$ III-tubulin ${ }^{+}$preplate in the same region in which Etv1 was upregulated and scattered ectopic $\beta$ IIItubulin ${ }^{+}$cells in the progenitor zone (Fig. $2 G, G^{\prime}$, arrowheads). Interestingly, this region of increased $\beta$ III-tubulin expression (Fig. $2 G^{\prime}$, arrowheads) coincided with the increased Blbp expression (Fig. $2 \mathrm{H}, \mathrm{H}^{\prime}$ ). We also analyzed Tbr1 expression in the same region, and found a similar increase, with a higher number of Tbr ${ }^{+}$cells in the Spry1-2 ${ }^{-1-}$ preplate compared to WT (Fig. S4, available at www.jneurosci.org as supplemental material).

Finally, we compared cell cycle exit in WT and Spry 1-2 $2^{-1-}$ brains by using a $24 \mathrm{~h}$ BrdU pulse. We found that Spry1-2 ${ }^{-1-}$ progenitors have a higher tendency of exiting the cell cycle compared to WT (Fig. S4 $A, A^{\prime}$, quantification in $A^{\prime \prime}$, available at www.jneurosci.org as supplemental material).

In summary, our loss-of-function analysis indicates that Spry1-2 inhibit progenitor cell maturation (repressing onset of Blbp expression), proliferation, and early neurogenesis.

\section{Frontal area expansion in Spry1/2 $2^{-/-}$cortex at E18.5}

Consistent with an upregulation and ectopic expression of molecular markers of the dorsomedial pallium and its progenitor pool, we found an increase in the size of frontal cortical areas. The LIM domain transcription factor Lmo4 marks borders between frontal/motor and somatosensory areas, and somatosensory with visual areas (Bulchand et al., 2003) (Fig. 3A, B,C). We analyzed Lmo4 expression by in situ hybridization in Spry1-2 $2^{-/-}$at E18.5 on sagittal and coronal sections; Lmo4 expression shifted caudally (Fig. $3 B^{\prime}$ ) and ventrally (Fig. $3 D^{\prime}$ ). This result was further confirmed by studying expression of $I d 2$, a member of the inhibitor of DNA binding (ID) family, which is strongly expressed in layers $2 / 3$ of rostrodorsal neocortex (Rubenstein et al., 1999) (Fig. 3E, arrowhead), in a domain that corresponds to the motor area. As with $L m o 4$, the $I d 2^{+}$domain shifted ventrally in the Spry 1-2 mutant rostral cortex (Fig. 3E'). Thus, Spry1-2 mutants show rostroventral expansion of molecular features of the frontal cortex; these findings are consistent with the molecular patterning changes and increased proliferation-neurogenesis in the rostral cortical progenitor domains at E12.5 (Figs. 1, 2).

\section{Spry 1-2 are expressed in different telencephalic domains at different times}

By E15.5 Spry1-2 expression showed important changes. Spry1 expression, analyzed by using Spry $1^{\text {lacz }}$ transgenic mice (Thum et al., 2008), showed strong expression in the septum (Fig. $4 A$, arrowheads), the cortical hem-medial pallium (Fig. $4 A$, arrows), and in diencencephalic and subcortical structures. Whereas
Spry2 expression was now low in the remnant of the RPC (the septum), and its expression was robust in the cortical ventricular/ subventricular zone (Fig. $4 B$, arrow), with rostrocaudal and ventrodorsal gradients. In addition, Spry2 RNA was present in the deep layer of the cortical plate (arrowhead).

We compared Spry1-2 expression at this stage to the pattern of Erk phosphorylation (a readout of Fgf signaling, see next paragraph). Strikingly, Spry2 and Erk phosphorylation (pErk) followed the same gradient in the ventricular/subventricular zone (VZ/SVZ) (Fig. 4, compare $B$ and $C$ ), consistent with hypothesis that Spry2 and pErk expression both reflect positive responses to Fgf signaling. Spry2 in turn would attenuate Fgf signaling and thereby may shape the gradient of MAPK activation. Finally, we compared Spry2 and pErk expression patterns to Coup-TFI, a gene repressed by Fgf signaling. Intriguingly, the pattern of CoupTFI expression was similar to pErk in the ventrodorsal axis, whereas it was opposite in the rostrocaudal axis.

In sum, comparing the E12.5 and E15.5 expression data suggests that Spry1-2 may have different regional functions at different times. In the next section we studied the Spry $2^{-/-}$cortical phenotype at E15.5, when Spry2 has its ventrodorsal expression gradient in the pallial progenitors.

\section{Spry2 negatively regulates Erk phosphorylation and proliferation and regulates dorsoventral molecular patterning of pallial progenitors}

Activation of the Erk1/2 MAPK is a general response that can be mediated by all FgfRs. Sprouty family members act intracellularly to negatively regulate Fgf signaling primarily via repressive effects on the MAPK pathway (Kim and Bar-Sagi, 2004). Thus, we examined the levels of activated MAPK (phosphorylated p42-p44, pErk) in Spry $2^{-/-}$using immunofluorescence. While at E12.5 we did not detect a change in Erk phosphorylation in Spry $2^{-1-}$ or Spry1-2 $2^{-/-}$(data not shown), by E15.5 we did detect increased 
E15.5
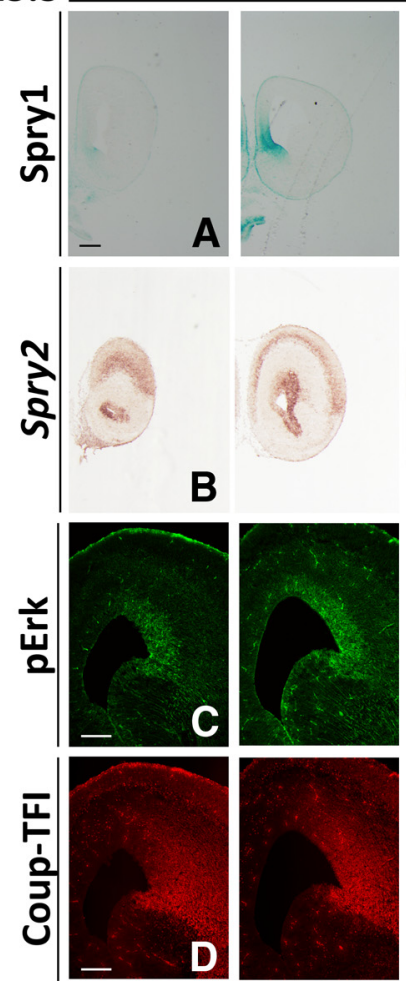

rostro-caudal axis
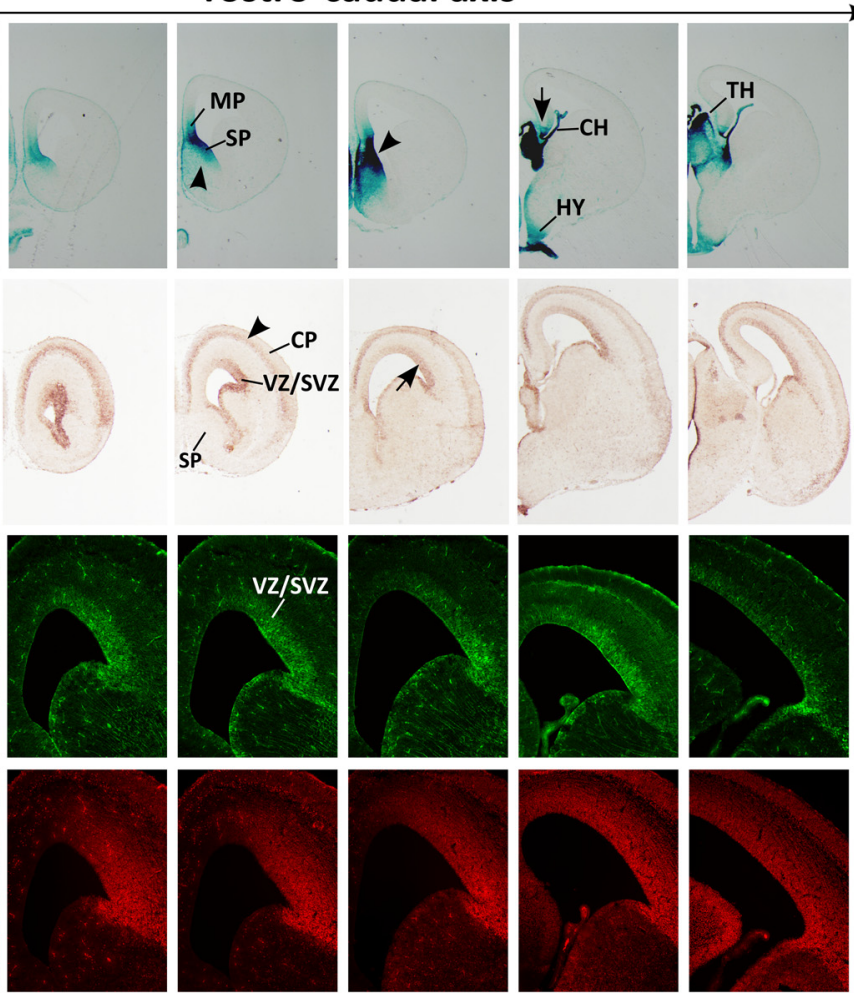
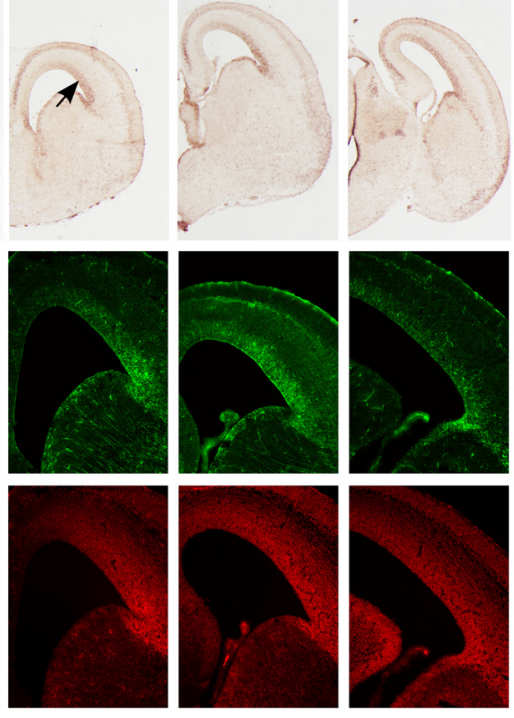

Figure 4. Spry1, Spry2, pErk, and Coup-TFl expression patterns in the telencephalon at E15.5. A, Assay for $\beta$-Gal activity on coronal sections of Spry $1^{\text {Lacz/+ }}$ transgenic mice, showing Spry1 expression in the septum, medial pallium, choroid plexus, hypothalamus, and thalamus. B, RNA in situ hybridization for Spry2. Spry2 expression is prominent in the cortical ventricular zone (arrow) with a high-ventral low-dorsal gradient. Its RNA is also present in the deep layer of the cortical plate (arrowhead). C, Immunofluorescence analysis of p42/p44 phosphorylation (pErk) pattern in the pallium. The immunostaining shows a highventral low-dorsal gradient in the VZ/SVZ similar to Spry2 expression. D, Coup-TFl immunofluorescence analysis showing the same ventrodorsal gradient as pErk and Spry2 in the VZ/SVZ.CP, Cortical plate; VZ/SVZ, ventricular zone/subventricular zone; SP, septum; MP, medial pallium; $\mathrm{CH}$, choroid plexus; TH, thalamus. Scale bar, $500 \mu \mathrm{m}$.

pErk levels. At E15.5 pErk $^{+}$cortical progenitors (VZ and SVZ) were present in a ventrodorsal gradient (Figs. $4 C$ and $5 A$ ), a pattern that resembles Spry2 and Coup-TFI expression (Fig. 4). In Spry $2^{-/-}$, pallial VZ/SVZ pErk staining was greatly expanded (Fig. $5 A, A^{\prime}$, arrowheads). We measured the dorsal spread of pErk expression in the dorsal pallium; there was a $77 \pm 37 \%$ SD $(p<$ $0.03 ; n=3$ ) increase in the Spry $2^{-/-}$brains.

Next, we assessed whether alterations in Spry2 dosage altered Fgf-regulated gene expression in the cortex at E15.5. We examined expression of the Fgf-responsive genes: Blbp, Etv1, and Mest; all three genes were expressed in the pallial VZ with a ventrodorsal gradient in a pattern similar to Spry 2 and pErk (Figs. $4 B, C$, $5 B, C, D)$. In the Spry $2^{-/-}$mutants this pallial expression increased for all three genes (Fig. $5 B^{\prime}-D^{\prime}$, arrowheads). We also tested whether Spry2 controls expression of Coup-TFI, a gene repressed by Fgf signaling. As at E12.5 (Fig. 1 D, $D^{\prime}$ ), Coup-TFI was repressed in the absence of Spry 2 in the VZ and in the IZ (Fig. $\left.5 E, E^{\prime}\right)$. Quantification of VZ/SVZ fluorescence intensity showed a significant decrease in Coup-TFI expression, which was most robust in the ventral pallium (Fig. $5 F$ ).

We then assessed whether alterations in Spry2 dosage and Erk activation had an effect on proliferation. First, we used the M phase marker phospho-histone-3 (PH3) to quantify the mitotic index. $\mathrm{PH} 3$ staining labels apical $\mathrm{VZ}$ and basal SVZ progenitors. We quantified the number of $\mathrm{PH}^{+}$cells in the $\mathrm{VZ}$ (Fig. 5G, $G^{\prime}$, arrows) and SVZ (Fig. 5G, $G^{\prime}$, boxes). Removal of Spry 2 increased the mitotic index of SVZ progenitors [Fig. $5 G, G^{\prime}$, boxes; quanti-

fication below (see Fig. 8C)] $(p<0.05$, $n=4)$. The $\mathrm{VZ}$ appeared to have increased $\mathrm{PH} 3^{+}$cells, although this was not statistically significant [Fig. $5 G, G^{\prime}$, arrows (see Fig. $8 B$ )]. Next, to study $\mathrm{S}$ phase of the cell cycle, we administered BrdU $1 \mathrm{~h}$ before harvesting the embryos (E15.5), and counted the number of BrdU ${ }^{+}$cells. Spry $2^{-/-}$had increased numbers of S-phase cells [Fig. $5 H, H^{\prime}$ and quantification below (see Fig. $8 E)](p<0.005, n=3)$.

Quantification of VZ length in WT and Spry 1-2 $2^{-1-}$ pallium showed a statistically significant increase of $\mathrm{VZ}$ extension in Spry1-2 $2^{-/-}$mutants $(\sim 14 \pm 6 \%$ SD, $p<0.02, n=3$ ) (Fig. S5, available at www. jneurosci.org as supplemental material), showing that Spry2 loss of function caused morphological abnormalities, probably related to increased proliferation in $\mathrm{VZ}$ and SVZ. Moreover, in 30\% of the E15.5 brains examined we detected a thinner cortical plate in Spry2 $2^{-/-}$cortices compared to WT.

In summary, these data show a role for Spry2 as a regulator of transcription and proliferation in the ventrodorsal pallium at the stage of mid-neurogenesis (E15.5).

\section{Coup-TFI overexpression induces Spry1-2 in dorsomedial cortex}

We have previously shown that when Coup-TFI is overexpressed in dorsomedial cortex using the D6 enhancer (D6/ Coup-TFI), there was a reduction in pErk (Faedo et al., 2008). Given the effects on pErk in Spry $2^{-/-}$, we investigated whether Coup-TFI overexpression was associated with changes in Spry1-2 RNA expression at E12.5 and E15.5.

Indeed, Coup-TFI overexpression at E12.5 resulted in increased Spry1-2 expression in the dorsomedial pallium (Fig. 6A$B^{\prime}$, arrowheads), overlapping with the area of Coup-TFI overexpression (Fig. $6 C, C^{\prime}$ ). This same region showed reduced pErk immunofluorescence (on adjacent sections) (Fig. $6 D, D^{\prime}$, arrowheads). Next, we performed the same assays at E15.5 when Spry 2 and Coup-TFI are expressed in the pallium with similar ventral-dorsal gradients (high-ventral low-dorsal) (Fig. 4). Whereas Spryl showed only small changes (Fig. 6E, $E^{\prime}$, arrowhead), Spry2 expression was increased in the ventral and dorsal pallium (Fig. $6 F, F^{\prime}$, arrowhead), in the region of high Coup-TFI overexpression. pErk immunofluorescence showed a profound reduction in the region in which Coup-TFI protein was overexpressed (Fig. $6 G-H^{\prime}$ ). We next examined Coup-TFI ${ }^{-/-}$-null mice at E12.5 and E15.5. We did not detect changes in Spry expression (data not shown), suggesting that other molecules, in addition to Coup-TFI, regulate their expression. On the other hand, we found that expression of Etv 5 and Etv 1 (Fgf-activated genes) were upregulated in the Coup-TFI ${ }^{-/-}$ventral pallium (Etv5) and dorsal LGE (Etv1) at E12.5 and E15.5, respectively (Fig. S6 A, $A^{\prime}, C, C^{\prime}$, available at www.jneurosci.org as supplemental material). Moreover, FgfR3 (Fgf-repressed gene), was downregulated in Coup$\mathrm{TFI}^{-/-}$mutants (Fig. S6 B, $B^{\prime}$, available at www.jneurosci.org as supplemental material). These data support the hypothesis that 


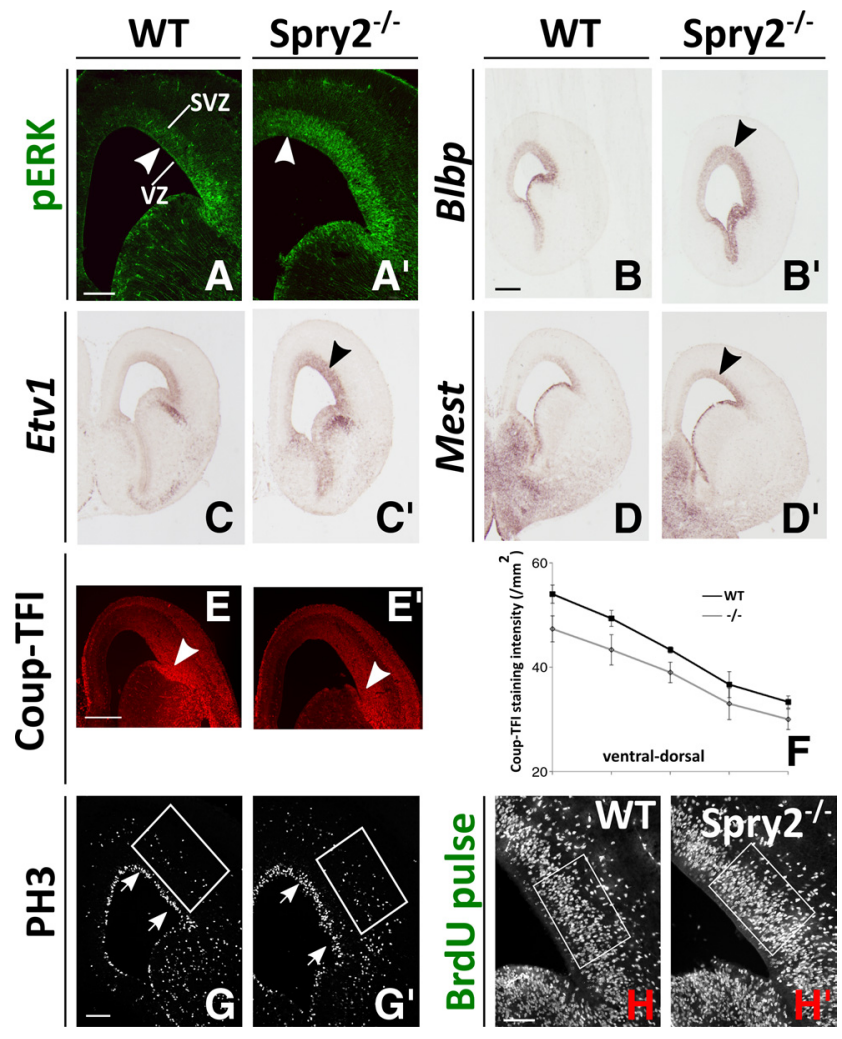

Figure 5. Spry2 regulates Erk phosphorylation, proliferation, and progenitor identity in pallial proliferative regions at E15.5. $\boldsymbol{A}, \boldsymbol{A}^{\prime}$, pErk immunofluorescence in WT $(\boldsymbol{A})$ and Spry2 ${ }^{-/-}\left(\boldsymbol{A}^{\prime}\right)$ brains, showing increased Erk activation in the VZ/SVZ. $\boldsymbol{B}-\boldsymbol{D}^{\prime}$, RNA in situ hybridization for $B l b p$ $\left(\boldsymbol{B}, \boldsymbol{B}^{\prime}\right)$, Etv1 $\left(\boldsymbol{C}, \boldsymbol{C}^{\prime}\right)$, and Mest $\left(\boldsymbol{D}, \boldsymbol{D}^{\prime}\right)$ in WT $(\boldsymbol{B}-\boldsymbol{D})$ and Spr2 ${ }^{-/-}\left(\boldsymbol{B}^{\prime}-\boldsymbol{D}^{\prime}\right)$ brains, showing the upregulation in the VZ/SVZ region for all three genes (arrowheads). $E, E^{\prime}$, Coup-TFl immunofluorescence in WT $(\boldsymbol{E})$ and Spry $2^{-1-}\left(\boldsymbol{E}^{\prime}\right)$ brains showing downregulation of Coup-TFl expression in the dorsal/ventral pallium. $\boldsymbol{F}$, Quantification of Coup-TFI staining intensity in the ventral-dorsal pallium in WT and Spry $2^{-/-}$brains in the ventral-dorsal axis. $\mathbf{G}, \mathbf{G}^{\prime}, \mathrm{PH} 3$ immunofluorescence in WT $(\boldsymbol{G})$ and Spry2 ${ }^{-/-}\left(\boldsymbol{G}^{\prime}\right)$; PH3 ${ }^{+}$cell quantification for VZ (between arrows in $\mathbf{G}, \boldsymbol{G}^{\prime}$ ) and SVZ (in the boxes in $\boldsymbol{G}, \boldsymbol{G}^{\prime}$ ) is shown in Figure $8 \boldsymbol{B}, \boldsymbol{C} . \boldsymbol{H}, \boldsymbol{H}^{\prime}, 60$ min pulse BrdU labeling of WT ( $\boldsymbol{H}$ ) and Spry $1-2^{-1-}\left(\boldsymbol{H}^{\prime}\right)$ at E15.5. Coronal sections were immunostained with anti-BrdU antibody. More BrdU ${ }^{+}$cells are present in the dorsal/ventral pallium in Spry7-2 ${ }^{-/-}$cortex $\left(\boldsymbol{H}^{\prime}\right)$ than in WT (H). BrdU ${ }^{+}$cells quantification is shown in Figure 8 E. Scale bars: $500 \mu \mathrm{m}$.

Coup-TFI negatively regulates Fgf signaling in the ventral pallium and subpallium. We suggest that increased levels of CoupTFI in the D6-COUP-TFI mouse revealed functions of this nuclear receptor that are subtle or masked in the Coup-TFI ${ }^{-1-}$ mouse, perhaps because of compensation by another gene.

\section{Spry2 is required for Coup-TFI repression of}

Fgf-regulated genes

Given our evidence that Coup-TFI promotes Spry2 expression, we assessed whether removing Spry 2 function altered the effect of overexpressing Coup-TFI in the dorsal pallium. First, we examined Erk phosphorylation; as previously shown (Faedo et al., 2008), Coup-TFI overexpression led to a striking downregulation of pErk (Fig. 7, compare $A$ and $A^{\prime \prime}$ ). However, eliminating Spry2 function in the D6/Coup-TFI mutants significantly rescued pErk levels (Fig. 7, compare arrows in $A^{\prime \prime}$ and $\left.A^{\prime \prime \prime}\right)$. We measured the length of $\mathrm{pErk}^{+}$domain in the dorsal pallium, and found a $92 \pm$ $39 \%$ SD $(p<0.005, n=3)$ increase in the Spry $2^{-/-}$;D6/CoupTFI brains compared to D6/Coup-TFI.

Next, we investigated the expression of the Fgf- and Spryresponsive genes Etv1, Blbp, and Mest. When Coup-TFI was overexpressed, we observed greatly reduced dorsal expression of Etv1
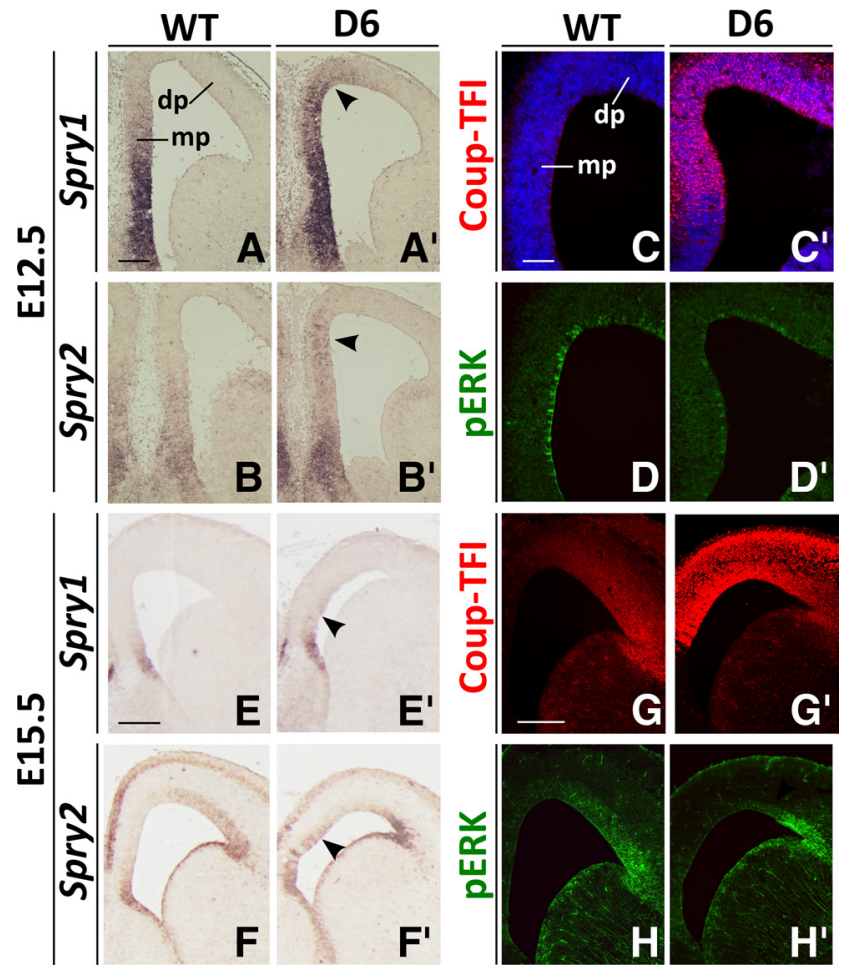

Figure 6. Coup-TFl overexpression induces Spry1-2. $A-B^{\prime}$, E12.5 RNA in situ hybridization for Spry $1\left(\boldsymbol{A}, \boldsymbol{A}^{\prime}\right)$ and Spry2 $\left(\boldsymbol{B}, \boldsymbol{B}^{\prime}\right)$ in WT $(\boldsymbol{A}, \boldsymbol{B})$ and D6/Coup-TFI $\left(\boldsymbol{A}^{\prime}, \boldsymbol{B}^{\prime}\right)$ telencephalons showing Spry1-2 ectopic expression in dorsal pallium (arrowheads in $\boldsymbol{A}^{\prime}$ and $\boldsymbol{B}^{\prime}$ ). $\boldsymbol{C}-\boldsymbol{D}^{\prime}$, E12.5 immunofluorescence analysis of Coup-TFI $\left(\boldsymbol{C}, \boldsymbol{C}^{\prime}\right)$ and pErk $\left(\boldsymbol{D}, \boldsymbol{D}^{\prime}\right)$ expression in WT $(\boldsymbol{C}, \boldsymbol{D})$ and D6/Coup-TFI $\left(\boldsymbol{C}^{\prime}, \boldsymbol{D}^{\prime}\right)$ telencephalons. $\boldsymbol{C}$ and $\boldsymbol{D}^{\prime}$ show adjacent sections of $\boldsymbol{A}$ and $\boldsymbol{B}^{\prime} . \boldsymbol{E}-\boldsymbol{F}^{\prime}, \mathbf{E} 15.5$ RNA in situ hybridization for $\operatorname{Spry} 1\left(\boldsymbol{E}, \boldsymbol{E}^{\prime}\right)$ and $\operatorname{Spry} 2\left(\boldsymbol{F}, \boldsymbol{F}^{\prime}\right)$ in WT $(\boldsymbol{E}, \boldsymbol{F})$ and D6/Coup-TFl $\left(\boldsymbol{E}^{\prime}, \boldsymbol{F}^{\prime}\right)$ telencephalons showing Spry2 ectopic expression in dorsal pallium (arrowheads in $\boldsymbol{E}^{\prime}$ and $\boldsymbol{F}^{\prime}$ ). $\mathbf{G}-\boldsymbol{H}^{\prime}$, E15.5 immunofluorescence analysis of Coup-TFI $\left(\boldsymbol{G}, \boldsymbol{G}^{\prime}\right)$ and pErk $\left(\boldsymbol{H}, \boldsymbol{H}^{\prime}\right)$ expression in WT $(\boldsymbol{G}, \boldsymbol{H})$ and D6/Coup-TFI $\left(\boldsymbol{G}^{\prime}, \boldsymbol{H}^{\prime}\right)$ telencephalons. $\boldsymbol{G}$ and $\boldsymbol{H}^{\prime}$ show adjacent sections of $\boldsymbol{A}$ and $\boldsymbol{B}^{\prime}$. dp, Dorsal pallium; mp, medial pallium. Scale bars: $200 \mu \mathrm{m}\left(\boldsymbol{A}-\boldsymbol{D}^{\prime}\right) ; 500 \mu \mathrm{m}$ $\left(E-H^{\prime}\right)$.

and Mest (Fig. $7 B^{\prime \prime}, D^{\prime \prime}$, arrowheads) and a reduction of VZ/SVZ thickness (Blbp) (Fig. $\left.7 C^{\prime \prime}\right)$. The introduction of the Spry2-null allele into the D6/Coup-TFI line rescued Etv1, Mest and Blbp expression levels in the dorsal pallium (Fig. 7, compare arrowheads in $B^{\prime \prime}$ and $B^{\prime \prime \prime} ; C^{\prime \prime}$ and $C^{\prime \prime \prime}$; and $D^{\prime \prime}$ and $\left.D^{\prime \prime \prime}\right)$.

Thus, these experiments show that increased levels of CoupTFI require Spry2 to reduce cortical Fgf signaling in the dorsal pallium.

\section{Loss of Spry2 rescues proliferation defects in D6/CoupTFI at E15.5}

We have previously shown that Coup-TFI promotes cell cycle withdrawal and neuronal differentiation (Faedo et al., 2008). Taking into account the decrease of pErk and the upregulation of Spry2 (Fig. 6) in D6/Coup-TFI, we investigated whether Spry2 played a role in regulating proliferation of cortical progenitors when Coup-TFI is overexpressed. We used the M phase marker $\mathrm{PH} 3$ to quantify the mitotic index. Quantification of $\mathrm{PH} 3{ }^{+}$cells showed that removal of Spry 2 in the D6/Coup-TFI cortex largely rescued the VZ and SVZ proliferation defects due to Coup-TFI overexpression (Fig. $8 A^{\prime \prime}, A^{\prime \prime \prime}$; quantification in $B$ and $\left.C\right)(p<$ $0.05, n=4)$.

Next, to study S phase of the cell cycle, we administered BrdU $1 \mathrm{~h}$ before harvesting the embryos (E15.5), and counted the number of $\mathrm{BrdU}^{+}$cells in the combined VZ and SVZ. Eliminating 


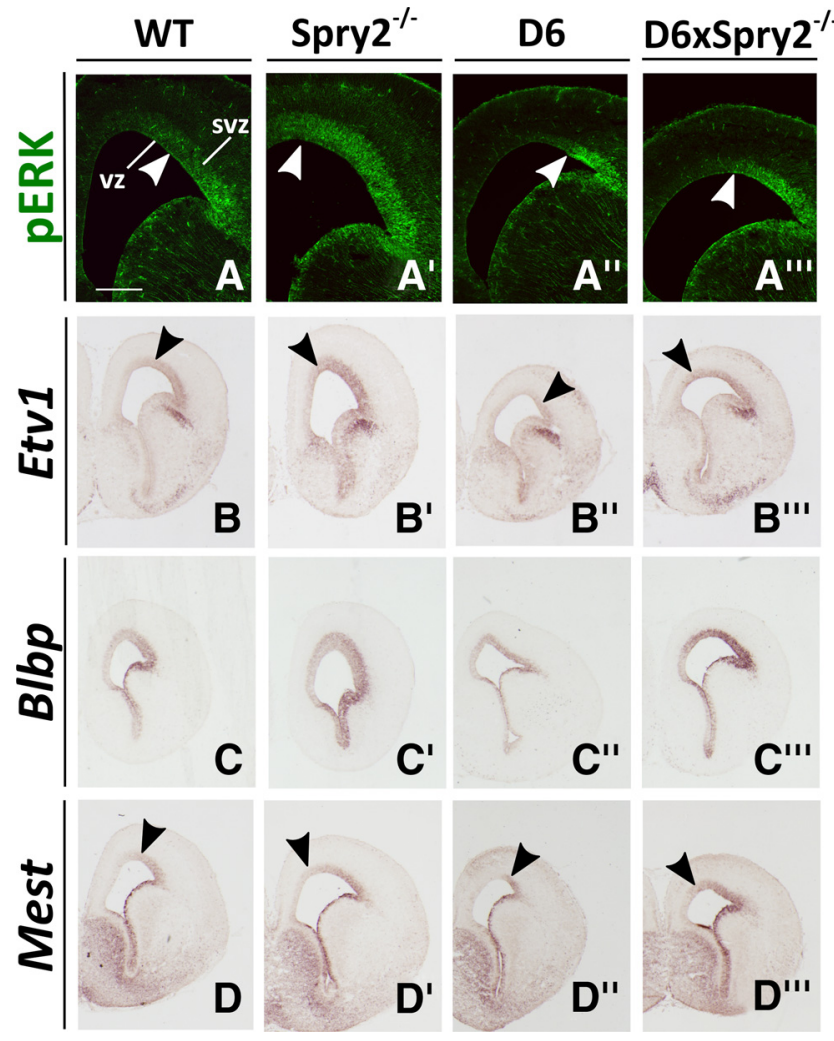

Figure 7. Spry $2^{-1-}$ rescues gene expression defects in E15.5 Coup-TFI overexpressing mice. $\boldsymbol{A}-\boldsymbol{A}^{\prime \prime \prime}$, Immunofluorescence at E15.5 showing phosphorylated Erk in WT (A), Spry $2^{-\prime}$ $\left(\boldsymbol{A}^{\prime}\right)$, D6/Coup-TFl $\left(\boldsymbol{A}^{\prime \prime}\right)$, and D6/Coup-TFl;Spry2 ${ }^{-/-}\left(\boldsymbol{A}^{\prime \prime \prime}\right)\left(\boldsymbol{A}\right.$ and $\boldsymbol{A}^{\prime}$ are the same panels as in Fig. 5; all the genotypes are littermates). pErk phenotype in Spry $2^{-1-}$ is described in Figure 5. Coup-TFl overexpression downregulates Erk activation $\left(A^{\prime \prime}\right)$; introduction of the Spry2-null allele into the D6/Coup-TFl genotype significantly rescued Erk phosphorylation $\left(A^{\prime \prime \prime}\right)$. Arrows in $A-A^{\prime \prime \prime}$ point to the dorsal extent of high pErk staining. We set the WT length to $100 \%$, and we measured pErk levels in the different genotypes. On average, Spry $2^{-/-}$showed a $177 \pm 30 \%$ SD increase, D6/Coup-TFl showed a reduction of $50 \pm 11 \%$ SD, whereas the D6/Coup-TFl; Spry $2^{-1-}$ showed levels similar to WT $\left(93 \pm 20 \%\right.$ SD). $A-D^{\prime \prime \prime}$, RNA in situ hybridization at E15.5 for Etv1 $\left(\boldsymbol{B}-\boldsymbol{B}^{\prime \prime \prime}\right)$, Blbp $\left(\boldsymbol{D}-\boldsymbol{D}^{\prime \prime \prime}\right)$, and Mest $\left(\boldsymbol{C}-\boldsymbol{C}^{\prime \prime \prime}\right)$ in WT $(\boldsymbol{B}-\boldsymbol{D})$, Spry2 ${ }^{-/-}\left(\boldsymbol{B}^{\prime}-\boldsymbol{D}^{\prime}\right)$, D6/Coup-TFI $\left(\boldsymbol{B}^{\prime \prime}-\boldsymbol{D}^{\prime \prime}\right)$, and D6/Coup-TFl;Spry2 ${ }^{-/-}\left(\boldsymbol{B}^{\prime \prime \prime}-\boldsymbol{D}^{\prime \prime \prime}\right)$. Fgf positively regulated genes were upregulated in Spry $2^{-/}$telencephalons (as described in Fig. 5; arrowheads in $\boldsymbol{B}^{\prime}-\boldsymbol{D}^{\prime}$ mark the increase in expression level), and downregulated in D6/Coup-TFl (arrowheads in $B^{\prime \prime}-D^{\prime \prime}$ mark the decrease in expression level). The gene expression defects in D6/Coup-TFI were rescued by the Spry $2^{-/-}$allele (arrowheads in $\boldsymbol{B}^{\prime \prime \prime}-\boldsymbol{D}^{\prime \prime \prime}$ point to the increase in expression level). VZ, Ventricular zone; SVZ, subventricular zone. Scale bar, $500 \mu \mathrm{m}$.

Spry2 function in the D6/Coup-TFI;Spry2 ${ }^{-1-}$ compound mutant partially rescued the number of cells in S phase (Fig. $8 D^{\prime \prime}, D^{\prime \prime \prime}$; quantification in $E)(p<0.005, n=3)$.

Thus, our data show that Spry2 negatively regulates cortical progenitor proliferation, and that Coup-TFI's repression of proliferation is largely mediated by Spry2 (Fig. S7, available at www. jneurosci.org as supplemental material).

\section{Discussion}

Here we show that Spry1 and Spry2 have distinct early and late functions in cortical development. At early stages (E12.5), Spry1 and Spry2 function together as negative regulators of Fgf signaling from the RPC to control patterning, proliferation, and differentiation of the rostral cortex. By E15.5, Spry2 has a function in regulating patterning and proliferation of the ventrolateral pallium. Finally, we present evidence that Coup-TFI promotes Spry expression, which mediates some of its Fgf-repressive properties (inhibition of Erk phosphorylation, proliferation, and Etv gene transcription).
Spry1-2 regulate molecular patterning of rostral cortical progenitors

Fgf signaling emanating from ligands produced by the RPC is perhaps the most important mechanism for specifying rostral identity of the cortex (Fukuchi-Shimogori and Grove, 2003; Garel et al., 2003; Storm et al., 2006; Cholfin and Rubenstein, 2007, 2008).

We found that Spry1-2 expression in the RPC (through E12.5) negatively regulated several aspects of Fgf signaling in cortical progenitors. Spry 1-2 $2^{-/-}$mutants showed increased rostral molecular properties, based on increased Etv4, Etv5 and Sp8 expression, and reduced expression of Coup-TFI and FgfR3 (Fig. 1). In addition, the Spry 1-2 $2^{-/-}$mutants showed reduced Axin2 expression (Fig. 1) indicative of Fgf's antagonistic effect on Wnt signaling in the forebrain (Fukuchi-Shimogori and Grove, 2003; Shimogori et al., 2004; Storm et al., 2006). Furthermore, reduced Wnt signaling is associated with increased cortical neurogenesis (Machon et al., 2007), as found at early stages in Spry1-2 $2^{-1-}$ mutants (Fig. 2). Thus, as at the midbrain-hindbrain patterning center (Basson et al., 2008), Spry1-2 have key functions in early forebrain patterning. Ongoing studies are aimed at elucidating Spry1 and Spry2's individual and combined functions in the RPC on development of the septum and adjacent rostral telencephalic structures, which also show molecular phenotypes (e.g., increased Blbp and Mest expression in the septum and rostral LGE) (Fig. 2).

Spry1-2 inhibit neurogenesis and progenitor cell maturation A recent paper demonstrated that Fgf10 expression in cortical progenitors contributes to the maturation of neuroepithelial cells into radial glia progenitors (Sahara and O'Leary, 2009). Our results may explain why this study reported that $\mathrm{Fg} f 10^{-/-}$mutants have a delay in radial glia cells formation that is biased for the rostral cortex (Sahara and O'Leary, 2009). Spry1-2, whose early expression is concentrated in rostral regions at early time points (Fig. S1, available at www.jneurosci.org as supplemental material), are excellent candidates for being negative feedback regulators of Fgf10-induced radial glia maturation. Thus, perhaps reducing Spry dosage in $\mathrm{Fgfl} \mathrm{O}^{-/-}$mutants would rescue their phenotype.

Consistent with this finding, we found that Spry1-2 inhibit radial glia maturation, based on increased Blbp expression (Fig. 2 ). Onset of Blbp is strictly correlated with the start of neurogenesis and radial glia directed neuronal migration, and almost all neurons in the mouse brain derive from $\mathrm{Blbp}^{+}$radial glia (Anthony et al., 2004). In Spry1-2 $2^{-1-}$ mutants the region of Blbp upregulation has increased neuronal differentiation based on increased numbers of basal progenitors (Tbr $2^{+}$), and increased numbers of preplate neurons ( $\beta$ III-tubulin ${ }^{+}, \mathrm{Tbrl}^{+}$and $E t v 1^{+}$) (Fig. 2). These findings show that Spry function is required to inhibit progenitor maturation in the dorsal/medial pallium.

Finally, loss of Spry1-2 function caused an expansion of cortical areas with rostral identity, as shown by the expression of Lmo4 and Id2 (Fig. 3). Thus, Spry1-2 negatively regulate Fgfdriven frontal (motor) area specification by modulating progenitor cell identity and differentiation.

\section{Later Spry functions in cortical development}

While at early developmental stages (through E12.5) Spry1 and Spry2 are coexpressed in the RPC, these genes show distinct telencephalic expression patterns by E15.5: Spry1 is expressed in the septum and cortical hem and Spry 2 in the cortical VZ and cortical plate (Fig. 4). Moreover, at E15.5 Spry2 has an expression pattern similar to pErk, characterized by a ventrodorsal gradient. At ear- 
lier stages (E12.5) pErk is observed throughout the telencephalic VZ; at this stage we could not detect changes in Erk activation in Spry 1-2 $2^{-/-}$brains, suggesting that the Spry genes have a stronger role in Erk activation at later developmental stages. Indeed, at E15.5 Spry $2^{-1-}$ mutants showed marked upregulation of pErk (Fig. 5), supporting a model that Spry genes have different effects on Erk activation in different spatial and temporal developmental contests.

Thus, here we demonstrated that at E15.5 Spry2 regulates proliferation, Fgf signaling and molecular patterning in the pallial progenitor zone. Spry2 $2^{-/-}$mutants showed increased proliferation (particularly in the SVZ), pErk levels and expression of Blbp, Mest and Etv1 (Figs. 6, 7). This demonstrates a role for Spry2-mediated inhibition of Fgf signaling within the cortical progenitors.

\section{Coup-TFI negatively regulates Fgf signaling through Sprouty}

The Coup-TFI orphan nuclear receptor has antagonistic functions to Fgf8 and Fgf17. Coup-TFI represses rostrodorsal cortical identity (Armentano et al., 2007; Faedo et al., 2008), and reduces pErk and pAkt levels while promoting cell cycle arrest and neurogenesis (Faedo et al., 2008). We presented several lines of evidence that Coup-TFI performs some of these functions (reducing pErk levels and promoting cell cycle arrest) at least in part through promoting Spry expression when Coup-TFI is overexpressed.

By using Coup-TFI gain-of-function experiments in the dorsal pallium (using the D6/Coup-TFI allele), we found that Coup-TFI can induce expression of Spry2 and to a lesser extent Spry1 (Fig. 6). Furthermore, removing Spry2 expression in the D6/Coup-TFI mutants partially rescued several of D6/Coup-TFI's prominent phenotypes, including decreased proliferation, and reduced expression of pErk, Blbp, Mest, and Evt1 (Figs. 7, 8). Thus, Spry2 function contributes to many of the phenotypes caused by Coup-TFI overexpression. An important question is whether the overexpression data are relevant for the physiological Coup-TFI expression in the ventral pallium. We analyzed Coup- $T F I^{-/-}$-null mice, and while we did not detect changes in Spry expression, we found that Coup-TFI alters the expression of three Fgf-regulated genes, Etv5, $F g f R 3$, and Etv1 in the ventral pallium and subpallium (Fig. S6, available at www.jneurosci.org as supplemental material). In particular, it is interesting to note that Etv5 is upregulated and FgfR3 downregulated at E12.5, in the ventral pallium of both Spry1$2^{-/-}$(Fig. 1) and Coup-TFI ${ }^{-/-}$mutants (Fig. S6, available at www. jneurosci.org as supplemental material).

The apparently unchanged Spry2 expression in the Coup$\mathrm{TFI}^{-/-}$mice may reflect the contribution of other transcription
B

B $\quad \mathrm{VZ}\left(\mathrm{PH}^{+}\right)$
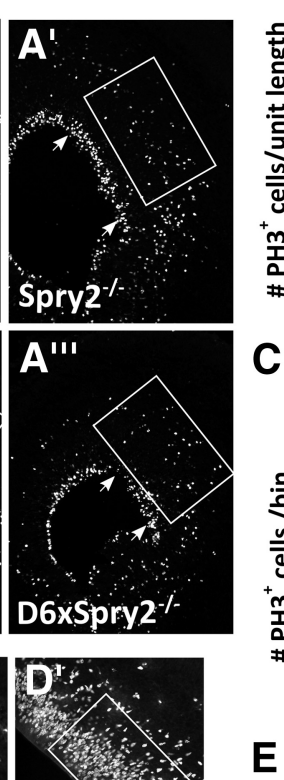

E

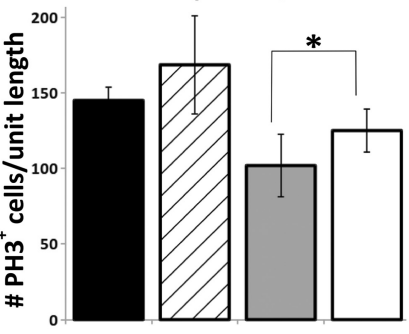

C $\quad \operatorname{SVZ}\left(\mathrm{PH}^{+}\right)$
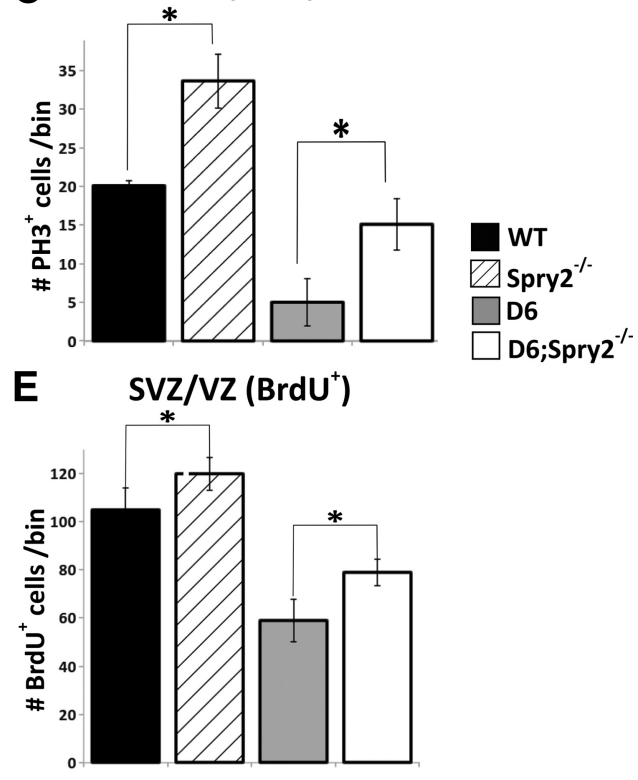

Figure 8. Spry2 rescues the Coup-TFl-induced proliferation defects at E15.5. $A-A^{\prime \prime \prime}$, PH3 immunofluorescence in WT $(A)$, Spry2 $2^{-/-}\left(\boldsymbol{A}^{\prime}\right)$, D6/Coup-TFI $\left(\boldsymbol{A}^{\prime \prime}\right)$, and in the compound mutant D6;Spry2 ${ }^{-/-}\left(\boldsymbol{A}^{\prime \prime \prime}\right)\left(\boldsymbol{A}, \boldsymbol{A}^{\prime}\right.$ and $\boldsymbol{D}, \boldsymbol{D}^{\prime}$ are the same in Fig. $G, G^{\prime}, H, H^{\prime}$; all the genotypes are littermates). $\boldsymbol{B}$, Quantification of $\mathrm{PH}^{+}{ }^{+}$cells in the VZ (cells counted in the region between the and normalized per unit length, $1 \mathrm{~mm}$ ). No statistically significant difference between WT and Spry $2^{-1}$ were ound, although there was a tendency toward an increase ( $p=0.2$, unpaired Student's test, $n=4)$. A statistically significant nce was found between D6/Coup-TFl and the compound mutant D6/Coup-TFl; Spry2 ${ }^{-1-}$ (unpaired Student's test, $p<$ C. Ouantification of $\mathrm{PH}^{+}{ }^{+}$cells in the SVZ (cells counted in the boxed region in $A-A^{\prime \prime \prime}$, and normalized for bin $1 \mathrm{~mm}^{2}$ ). statistically significant difference was found between all the genotypes (WT-Spry ${ }^{-/-} p<0.05$, WT-D6/Coup-TFI $p<0.05$, D6/Coup-TFI-D6/Coup-TFl;Spry2 ${ }^{-/} p<0.02$, unpaired Student's test, $\left.n=4\right)$. D- $\mathbf{D}^{\prime \prime \prime}$, BrdU immunofluorescence after $1 \mathrm{~h} \mathrm{BrdU}$ ulse at E15.5 in WT (D), Spry2 ${ }^{-\prime-}\left(\boldsymbol{D}^{\prime}\right)$, D6/Coup-TFI $\left(\boldsymbol{D}^{\prime \prime}\right)$, and in the compound mutant D6;Spry2 ${ }^{-/-}\left(D^{\prime \prime \prime}\right)$. $E$, Quantification of found between all the genotypes (WT-Spry2 ${ }^{-1-} p<0.005$, WT-D6/Coup-TFI $p<0.005$, D6/Coup-TFI-D6/Coup-TFI;Spry2 ${ }^{-1-}$ $p<0.005$, unpaired Student's test, $n=3)$. VZ, Ventricular zone; SVZ, subventricular zone. Scale bar, $500 \mu \mathrm{m}$.

factors that can drive Spry2 expression. Thus, we propose that COUP-TFI overexpression has revealed Coup-TFI functions that are masked in the Coup-TFI ${ }^{-1-}$ mutant by compensation.

Together, these data support the hypothesis that Coup-TFI negatively modulates Fgf signaling in the telencephalon, at least in part through promoting Spry expression.

\section{Model of Sprouty regulation of cortical patterning}

We propose models of Spry regulation of early and late cortical patterning (Fig. S7, available at www.jneurosci.org as supplemental material). At early stages (through E12.5) Spry1-2 expression in the RPC cooperates to repress Fgf signaling in the rostral cortex, thus controlling Etv genes and Coup-TFI/FgfR3. Moreover, Spry1-2 inhibit progenitor maturation: in their absence, there is an increase in radial glial marker expression (Blbp), pro- 
liferation, and early differentiation. Later in development (by E15.5), Spry2 is expressed in cortical progenitors of the ventrolateral pallium, in which it represses Erk activation and proliferation and regulates expression of Fgf-responsive genes. Thus, Spry regulation of Fgf signaling from the RPC and the ventral pallium has potent and temporally distinct roles in modulating cortical development.

\section{References}

Anthony TE, Klein C, Fishell G, Heintz N (2004) Radial glia serve as neuronal progenitors in all regions of the central nervous system. Neuron 41:881-890.

Armentano M, Chou SJ, Tomassy GS, Leingärtner A, O’Leary DD, Studer M (2007) COUP-TFI regulates the balance of cortical patterning between frontal/motor and sensory areas. Nat Neurosci 10:1277-1286.

Arnold SJ, Huang GJ, Cheung AF, Era T, Nishikawa S, Bikoff EK, Molnár Z, Robertson EJ, Groszer M (2008) The T-box transcription factor Eomes/ Tbr2 regulates neurogenesis in the cortical subventricular zone. Genes Dev 22:2479-2484.

Basson MA, Akbulut S, Watson-Johnson J, Simon R, Carroll TJ, Shakya R, Gross I, Martin GR, Lufkin T, McMahon AP, Wilson PD, Costantini FD, Mason IJ, Licht JD (2005) Sproutyl is a critical regulator of GDNF/RETmediated kidney induction. Dev Cell 8:229-239.

Basson MA, Echevarria D, Ahn CP, Sudarov A, Joyner AL, Mason IJ, Martinez S, Martin GR (2008) Specific regions within the embryonic midbrain and cerebellum require different levels of FGF signaling during development. Development 135:889-898.

Borello U, Cobos I, Long JE, McWhirter JR, Murre C, Rubenstein JL (2008) FGF15 promotes neurogenesis and opposes FGF8 function during neocortical development. Neural Dev 3:17.

Bulchand S, Subramanian L, Tole S (2003) Dynamic spatiotemporal expression of LIM genes and cofactors in the embryonic and postnatal cerebral cortex. Dev Dyn 226:460-469.

Bulfone A, Martinez S, Marigo V, Campanella M, Basile A, Quaderi N, Gattuso C, Rubenstein JL, Ballabio A (1999) Expression pattern of the Tbr2 (Eomesodermin) gene during mouse and chick brain development. Mech Dev 84:133-138.

Cholfin JA, Rubenstein JL (2007) Patterning of frontal cortex subdivisions by Fgf17. Proc Natl Acad Sci U S A 104:7652-7657.

Cholfin JA, Rubenstein JL (2008) Frontal cortex subdivision patterning is coordinately regulated by Fgf8, Fgf17, and Emx2. J Comp Neurol 509:144-155

Crossley PH, Martinez S, Ohkubo Y, Rubenstein JL (2001) Coordinate expression of Fgf8, Otx2, Bmp4, and Shh in the rostral prosencephalon during development of the telencephalic and optic vesicles. Neuroscience 108:183-206.

Englund C, Fink A, Lau C, Pham D, Daza RAM, Bulfone A, Kowalczyk T, Hevner RF (2005) Pax6, Tbr2, and Tbr1 are expressed sequentially by radial glia, intermediate progenitor cells, and postmitotic neurons in developing neocortex. J Neurosci 25:247-251.

Faedo A, Tomassy GS, Ruan Y, Teichmann H, Krauss S, Pleasure SJ, Tsai SY, Tsai MJ, Studer M, Rubenstein JL (2008) COUP-TFI coordinates cortical patterning, neurogenesis, and laminar fate and modulates MAPK/ ERK, AKT, and beta-catenin signaling. Cereb Cortex 18:2117-2131.

Feng L, Hatten ME, Heintz N (1994) Brain lipid-binding protein (BLBP): a novel signaling system in the developing mammalian CNS. Neuron 12:895-908.

Fukuchi-Shimogori T, Grove EA (2001) Neocortex patterning by the secreted signaling molecule FGF8. Science 294:1071-1074.

Fukuchi-Shimogori T, Grove EA (2003) Emx2 patterns the neocortex by regulating FGF positional signaling. Nat Neurosci 6:825-831.

Garel S, Huffman KJ, Rubenstein JL (2003) Molecular regionalization of the neocortex is disrupted in Fgf8 hypomorphic mutants. Development 130:1903-1914.

Gutin G, Fernandes M, Palazzolo L, Paek H, Yu K, Ornitz DM, McConnell SK, Hébert JM (2006) FGF signalling generates ventral telencephalic cells independently of SHH. Development 133:2937-2946.

Hébert JM, Lin M, Partanen J, Rossant J, McConnell SK (2003) FGF signaling through FGFR1 is required for olfactory bulb morphogenesis. Development 130:1101-1111.

Jho EH, Zhang T, Domon C, Joo CK, Freund JN, Costantini F (2002) Wnt/
beta-catenin/Tcf signaling induces the transcription of Axin2, a negative regulator of the signaling pathway. Mol Cell Biol 22:1172-1183.

Kim HJ, Bar-Sagi D (2004) Modulation of signalling by Sprouty: a developing story. Nat Rev Mol Cell Biol 5:441-450.

Klein OD, Minowada G, Peterkova R, Kangas A, Yu BD, Lesot H, Peterka M, Jernvall J, Martin GR (2006) Sprouty genes control diastema tooth development via bidirectional antagonism of epithelial-mesenchymal FGF signaling. Dev Cell 11:181-190.

Korada S, Zheng W, Basilico C, Schwartz ML, Vaccarino FM (2002) Fibroblast growth factor 2 is necessary for the growth of glutamate projection neurons in the anterior neocortex. J Neurosci 22:863-875.

Machon O, Backman M, Machonova O, Kozmik Z, Vacik T, Andersen L, Krauss S (2007) A dynamic gradient of Wnt signaling controls initiation of neurogenesis in the mammalian cortex and cellular specification in the hippocampus. Dev Biol 311:223-237.

Mason I (2007) Initiation to end point: the multiple roles of fibroblast growth factors in neural development. Nat Rev Neurosci 8:583-596.

Münchberg SR, Ober EA, Steinbeisser H (1999) Expression of the Ets transcription factors erm and pea3 in early zebrafish development. Mech Dev 88:233-236.

Qiu Y, Pereira FA, DeMayo FJ, Lydon JP, Tsai SY, Tsai MJ (1997) Null mutation of mCOUP-TFI results in defects in morphogenesis of the glossopharyngeal ganglion, axonal projection, and arborization. Genes Dev 11:1925-1937.

Raible F, Brand M (2001) Tight transcriptional control of the ETS domain factors Erm and Pea3 by Fgf signaling during early zebrafish development. Mech Dev 107:105-117.

Roehl H, Nüsslein-Volhard C (2001) Zebrafish pea3 and erm are general targets of FGF8 signaling. Curr Biol 11:503-507.

Rubenstein JL, Anderson S, Shi L, Miyashita-Lin E, Bulfone A, Hevner R (1999) Genetic control of cortical regionalization and connectivity. Cereb Cortex 9:524-532.

Sahara S, O'Leary DD (2009) Fgf10 regulates transition period of cortical stem cell differentiation to radial glia controlling generation of neurons and basal progenitors. Neuron 63:48-62.

Sahara S, Kawakami Y, Izpisua Belmonte JC, O’Leary DD (2007) Sp8 exhibits reciprocal induction with Fgf8 but has an opposing effect on anteriorposterior cortical area patterning. Neural Dev 2:10.

Sansom SN, Hébert JM, Thammongkol U, Smith J, Nisbet G, Surani MA, McConnell SK, Livesey FJ (2005) Genomic characterisation of a Fgf-regulated gradient-based neocortical protomap. Development 132:3947-3961.

Sessa A, Mao CA, Hadjantonakis AK, Klein WH, Broccoli V (2008) Tbr2 directs conversion of radial glia into basal precursors and guides neuronal amplification by indirect neurogenesis in the developing neocortex. Neuron 60:56-69.

Shim K, Minowada G, Coling DE, Martin GR (2005) Sprouty2, a mouse deafness gene, regulates cell fate decisions in the auditory sensory epithelium by antagonizing FGF signaling. Dev Cell 8:553-564.

Shimamura K, Rubenstein JL (1997) Inductive interactions direct early regionalization of the mouse forebrain. Development 124:2709-2718.

Shimogori T, Banuchi V, Ng HY, Strauss JB, Grove EA (2004) Embryonic signaling centers expressing BMP, WNT and FGF proteins interact to pattern the cerebral cortex. Development 131:5639-5647.

Smith KM, Ohkubo Y, Maragnoli ME, Rasin MR, Schwartz ML, Sestan N, Vaccarino FM (2006) Midline radial glia translocation and corpus callosum formation require FGF signaling. Nat Neurosci 9:787-797.

Storm EE, Garel S, Borello U, Hebert JM, Martinez S, McConnell SK, Martin GR, Rubenstein JL (2006) Dose-dependent functions of Fgf8 in regulating telencephalic patterning centers. Development 133:1831-1844.

Thomson RE, Kind PC, Graham NA, Etherson ML, Kennedy J, Fernandes AC, Marques CS, Hevner RF, Iwata T (2009) Fgf receptor 3 activation promotes selective growth and expansion of occipitotemporal cortex. Neural Dev 4:4.

Thum T, Gross C, Fiedler J, Fischer T, Kissler S, Bussen M, Galuppo P, Just S, Rottbauer W, Frantz S, Castoldi M, Soutschek J, Koteliansky V, Rosenwald A, Basson MA, Licht JD, Pena JT, Rouhanifard SH, Muckenthaler MU, Tuschl T, et al. (2008) MicroRNA-21 contributes to myocardial disease by stimulating MAP kinase signalling in fibroblasts. Nature 456:980-984.

Ye W, Shimamura K, Rubenstein JL, Hynes MA, Rosenthal A (1998) FGF and Shh signals control dopaminergic and serotonergic cell fate in the anterior neural plate. Cell 93:755-766. 